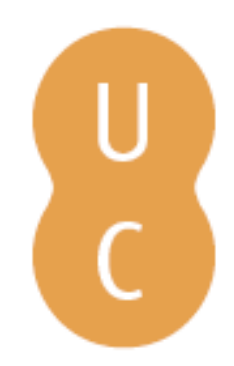

\title{
nombalina
}

\section{O Brasil em 2030: navegar num mar revolto}
Autor(es):
Vasconcelos, Álvaro
Publicado por: Imprensa da Universidade de Coimbra
URL persistente:
URI:http://hdl.handle.net/10316.2/43156
DOI:
DOI:https://doi.org/10.14195/978-989-26-1433-5_1

Accessed : $\quad$ 26-Apr-2023 12:03:20

A navegação consulta e descarregamento dos títulos inseridos nas Bibliotecas Digitais UC Digitalis, UC Pombalina e UC Impactum, pressupõem a aceitação plena e sem reservas dos Termos e Condições de Uso destas Bibliotecas Digitais, disponíveis em https://digitalis.uc.pt/pt-pt/termos.

Conforme exposto nos referidos Termos e Condições de Uso, o descarregamento de títulos de acesso restrito requer uma licença válida de autorização devendo o utilizador aceder ao(s) documento(s) a partir de um endereço de IP da instituição detentora da supramencionada licença.

Ao utilizador é apenas permitido o descarregamento para uso pessoal, pelo que o emprego do(s) título(s) descarregado(s) para outro fim, designadamente comercial, carece de autorização do respetivo autor ou editor da obra.

Na medida em que todas as obras da UC Digitalis se encontram protegidas pelo Código do Direito de Autor e Direitos Conexos e demais legislação aplicável, toda a cópia, parcial ou total, deste documento, nos casos em que é legalmente admitida, deverá conter ou fazer-se acompanhar por este aviso.

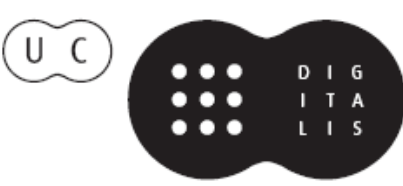




\section{Euro-Atlântico:}

\section{Espaço de Diálogos}

Isabel Maria Freitas Valente

Iranilson Buriti de Oliveira

(Coord)

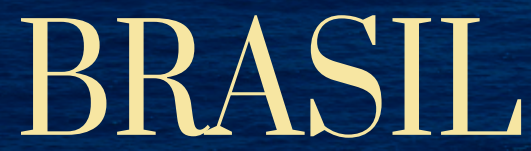

NAS ONDAS

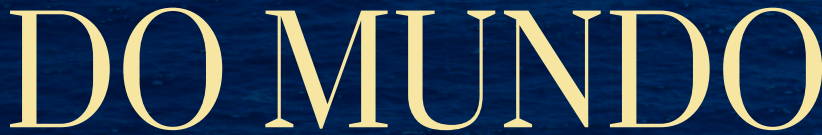

Álvaro Vasconcelos (Org)

Editora da Universidade Federal de Campina Grande

Imprensa da Universidade de Coimbra

2017 


\section{O BRASIL EM 2030: NAVEGAR NUM MAR REVOLTO}

Álvaro Vasconcelos

CEIS20-UC

E-mail: amdevasconcelos@gmail.com

\section{Resumo}

A diversidade, o empoderamento dos cidadãos, a difusão do poder e a emergência de um mundo policêntrico são quatro megatendências que marcam já a atualidade e condicionam os tempos que se avizinham, tendo como horizonte o ano de 2030. Este texto aborda a influência destas tendências na definição do futuro do Brasil, bem como o impacto que a realidade brasileira pode ter na cena internacional.

Palavras-chave: difusão do poder; diversidade; empoderamento; policentrismo

\section{Abstract}

Diversity, the empowerment of citizens, the diffusion of power and the emergence of a polycentric world are four megatrends already identifiable worldwide that will have a strong impact in the future ahead, in the horizon of 2030. This text addresses the influence of these trends in the future of Brazil as well as the impact that the Brazilian reality may have on the international scene.

Keywords: diffusion of power; diversity; empowerment; polycentrism 
(Página deixada propositadamente em branco.) 


\section{Introdução}

Este texto tem como ponto de partida dois relatórios sobre tendências mundiais para 2030: o europeu, elaborado a pedido da União Europeia, sob a minha coordenação ${ }^{2}$, e o norte-americano ${ }^{3}$. A partir das megatendências ali identificadas, o objetivo é analisar a sua influência no futuro do Brasil, particularmente no futuro dos seus cidadãos.

Começando por sublinhar a tendência para a diversidade, abordará três grandes tendências identificadas nos relatórios mencionados: o empoderamento dos cidadãos, a difusão do poder, e a emergência de um mundo policêntrico. Num capítulo final procurarei compreender como as três megatendências interagem.

O objetivo dos relatórios sobre tendências mundiais tem sido precisamente identificar tendências atuais suscetíveis de moldar o futuro, tendo como horizonte 2030. A dificuldade destes exercícios é lidar com o enorme grau de imprevisibilidade que as crises e os fatores de descontinuidade, os chamados Black Swans ${ }^{4}$, raros mas com impacto extremo, introduzem. Sempre que possível, será feita uma referência aos potenciais fatores de imprevisibilidade.

2 VASCONCELOS, Álvaro (ed.) - Global Trends 2030: Citizens in an Interconnected and Polycentric World. Paris: EUISS, 2012. Consultado em 13.07.2017. Disponível em https://www.iss.europa.eu/sites/default/files/EUISSFiles/ESPAS_report_01_0.pdf.

3 National Intelligence Council - Global trends 2030: Alternative worlds. Washington DC: NIC, 2012. Consultado em 13.07.2017. Disponível em: https://globaltrends2030.files. wordpress.com/2012/11/global-trends-2030-november2012.pdf

4 TALEB, Nassim N. - The Black Swan: The Impact of the Highly Improbable. Nova Iorque: Random House, 2007. 
Dos relatórios da União Europeia ${ }^{5}$ ressaltam três tendências que parecem particularmente relevantes para o futuro do Brasil: o empoderamento dos cidadãos, a difusão do poder e a tendência para um mundo policêntrico. A estas é necessário acrescentar a tendência para a diversidade, resultante de vários fatores e não só das migrações globais. A relação entre estas tendências pode ser a questão decisiva para compreender os desafios da governação nacional e global durante os próximos anos.

A análise do impacto a longo prazo das megatendências identificadas é perturbada pela gravidade da atual crise brasileira e a dificuldade de prever como e quando será superada. A crise é ela própria consequência das dificuldades do sistema político brasileiro em adaptar-se às tormentas que sopraram desde 2008 - a crise financeira global introduziu um grave favor de descontinuidade no crescimento económico e social do Brasil neste século.

Independentemente de crises e fatores de descontinuidade, podemos afirmar que as megatendências identificadas de empoderamento e de difusão do poder permitem cenários alternativos para o futuro: um de convergência, de inclusão e multilateralismo, e outro de fragmentação. Cenários intermédios são possíveis, mas o dilema «inclusão ou fragmentação" tipifica bem as alternativas sobre as quais é necessário e possível agir.

\section{Diversidade global}

O mundo em 2030 será habitat de 8,5 mil milhões de humanos - e os brasileiros deverão ser 225 milhões. Em 2017 a população brasileira

5 Em 2015, a União Europeia publicou um novo relatório (Global Trends to 2030: Can the EU meet the challenges ahead?) que identifica no essencial as mesmas tendências, mas aborda com mais detalhe as suas implicações para a União Europeia. Consultado em 13.07.2017. Disponível em http://espas.eu/orbis/sites/default/files/generated/document/ en/espas report 2015.pdf 
é de 209 milhões, dos quais cerca de 103 milhões de homens e 106 milhões de mulheres.

Tabela I - Evolução da população mundial e brasileira (em milhões)

\begin{tabular}{|l|c|c|c|c|c|}
\hline & $\begin{array}{c}\text { População } \\
\text { brasileira } \\
2017\end{array}$ & $\begin{array}{c}\text { População } \\
\text { brasileira } \\
2050\end{array}$ & $\begin{array}{c}\text { População } \\
\text { Mundial 2017 }\end{array}$ & $\begin{array}{c}\text { População } \\
\text { Mundial 2030 }\end{array}$ & $\begin{array}{c}\text { População } \\
\text { Mundial 2050 }\end{array}$ \\
\hline Total & 209 & 233 & 7.555 & 8.551 & 9.771 \\
\hline
\end{tabular}

Fonte: United Nations Department of Economic and Social Affairs/Population Division, World Population Prospects: The 2017 Revision, Key Findings and Advance Tables ${ }^{6}$

Uma megatendência pouco realçada nos relatórios referidos é a da diversidade humana. A diversidade irá aumentar, transformando a maioria dos países em autênticas torres de Babel, com uma enorme pluralidade de pertenças e de memórias históricas, culturais, linguísticas e religiosas. O mito da homogeneidade dos Estados ditos unitários é posto em causa e, muito provavelmente, continuará a sê-lo cada vez mais nos próximos 15 anos.

Os principais fatores da diversidade são os fluxos mundiais de migrações, facilitados pela globalização económica e pela contínua disparidade de renda e de oportunidades entre os países, pelos progressos nos meios de transporte e pela abertura de fronteiras, bem como por fatores demográficos. Uma das características desta migração global é a sua diversidade, quer em número de países de origem e de destino, quer do ponto vista cultural, linguístico e religioso.

De acordo com as Nações Unidas7, em 2000 havia 173 milhões de migrantes no mundo, número que subiu para 244 milhões em 2015. A

${ }^{6}$ ONU, Department of Economic and Social Affairs, Population Division - World Population Prospects: The 2017 Revision, Key Findings and Advance Tables. Working Paper No. ESA/P/WP/248, 2017. Consultado em 20.07.2017. Disponível em https://esa. un.org/unpd/wpp/Publications/Files/WPP2017_KeyFindings.pdf

7 ONU, Department of Economic and Social Affairs, Population Division - International Migration Report 2015: Highlights. (ST/ESA/SER.A/375), 2016. Consultado em 23.07.2017. 
América do Sul não acolheu um número significativo de emigrantes, atingindo 4,215 milhões em 2000 e 5,826 milhões em 2015. O número total de emigrantes vivendo no Brasil era de 684 mil em 2000, passando para 713 mil em 2015.

O Brasil, país que se fez graças a vagas sucessivas de imigrantes, conheceu nos anos de crescimento económico um salto no número de emigrantes, que passaram de 50 mil entradas, em 2009, para 102 mil em 2013. O número começou a diminuir em $2014^{8}$, mas deverá voltar a aumentar assim que a crise for ultrapassada, tendo igualmente em consideração o impacto que terá no mercado de trabalho o envelhecimento da sua população no horizonte de 2030. Os fluxos migratórios, como mostra o caso brasileiro, já não se reduzem ao sentido sul-norte, com a emergência dos fluxos no sentido sul-sul e mesmo no sentido norte-sul.

A diversidade do Brasil não é menor, apesar do país ter estado fora dos grandes fluxos migratórios. De acordo com o censo de 2010, no ano 2000 53,7\% dos brasileiros declaravam-se brancos e em 2010 eram já só $47,7 \%$, com a maioria, $(50,7 \%)$ a declarar-se preto ou pardo (mulato) 9 .

A afirmação da diversidade adormecida ou até recentemente oculta é a consequência da difusão do poder do Estado central para as regiões e da maior capacidade dos cidadãos empoderados de afirmarem os direitos das minorias a que pertencem, como tem sido particularmente o caso dos direitos LGBT, que no Brasil ganhou enorme importância e teve conquistas importantes na defesa da diversidade sexual nas últimas décadas. É natural que a afirmação dos direitos dos negros e dos índios também venha a contribuir para a perceção da diversidade brasileira.

Disponível em http://www.un.org/en/development/desa/population/migration/publications/migrationreport/docs/MigrationReport2015_Highlights.pdf

${ }^{8}$ Ver Cai entrada de imigrantes no Brasil, aponta pesquisa, com dados da Fundação Getúlio Vargas. Consultado em 20.07.2017. Disponível em http://www.bbc.com/portuguese/noticias/2015/12/151201_imigracao_brasil_jc,

9 Ver Censo 2010 mostra as características da população brasileira. Consultado em 26.07.2017. Disponível em .http://www.brasil.gov.br/educacao/2012/07/censo-2010-mostra-as-diferencas-entre-caracteristicas-gerais-da-populacao-brasileira 
A crescente diversidade religiosa é outra das tendências fortes do Brasil, país tradicionalmente católico, tendo a população evangélica subido de $9 \%$ em 1991, para $15,4 \%$ em 2000 e para $22,2 \%$ no censo de $2010 .{ }^{10}$ Se este ritmo de crescimento se mantiver, em 2030 cerca de $40 \%$ da população brasileira será evangélica. Esta tendência poderá ter um impacto político significativo, dada a agenda política conservadora da maioria dos movimentos evangélicos.

\section{O Brasil e o empoderamento dos cidadãos}

A tendência mais determinante do futuro da vida em sociedade é a do empoderamento dos cidadãos, em consequência da emergência da classe média, da saída da pobreza de milhões de indivíduos, da emancipação das mulheres, da universalização das tecnologias de informação e do progresso na educação e na saúde.

\section{Crescimento da classe média}

Em 2030 o Brasil deverá atingir 223 milhões de habitantes, pertencendo a sua larga maioria à classe média, que hoje representa cerca de $58 \%$ da sua população.

O crescimento espetacular da classe média a nível global irá, muito provavelmente, ter um impacto social e político muito significativo. A maioria dos cidadãos do mundo deixará de ser pobre para integrar a classe média - de 1.8 mil milhões, em 2009, para 3.2 mil milhões, em 2020, para 4.9 mil milhões, em 2030. O crescimento mais espetacular terá lugar na região da Ásia Pacífico, que representará 66\% da classe média mundial. Este desenvolvimento tem sido a força motora da emergência de países como a China e a Índia, mas também como o Brasil.

Porque a definição de classe média não é consensual, para os dados globais utilizamos a definição de Kharas e Gertz para quem pertence à

10 IBGE - Censo Demográfico 2010. Características Gerais da População, Religião e Pessoas com Deficiência. Rio de Janeiro: IBGE, 2012 
classe média quem tem um rendimento diário entre USD10 e USD100 em PPP. ${ }^{11}$

O crescimento da classe média brasileira não foi menos significativo do que o da chinesa ou do que o da indiana. Segundo Marcelo Neri, entre 1993 e 2011, 60 milhões de brasileiros terão saído da pobreza e integrado a classe média, tendo provimentos entre USD400 e USD1300, constituindo o que ele chamou de nova classe média. ${ }^{12}$

Os baixos índices atuais de crescimento económico mundial tornam difícil prever, a médio prazo, o crescimento da classe média, nomeadamente, segundo Kharas, de países como o Brasil.13 Segundo as projeções de Kharas, a classe média brasileira continuará a crescer, mas a um ritmo mais lento, o que levará a que, em 2030, venha a ser ultrapassado pela Indonésia e o México, em termos de consumo per capita da classe média.

A classe média brasileira continuará a crescer, mas, como não é provável que o crescimento do PIB brasileiro seja muito significativo nos próximos anos, o seu ritmo do crescimento irá desacelerar, não se prevendo que praticamente toda a população tenha saído da pobreza em 2030, como aconteceria se a classe média continuasse a crescer ao ritmo da primeira década do século. A partir de 2014 dá-se um travão no crescimento da classe média, com uma recessão de $-3,8 \%$ do produto em 2015 e -3,2\% em 2016, tendo como consequência uma queda do rendimento médio das famílias de $7 \%$, logo em 2015, que se agrava para $14 \%$ entre os $5 \%$ mais pobres, em consequência de vários fatores "como recessão, inflação alta e desemprego, mas sobretudo o congelamento

11 KHARAS, H. e GERTZ, G. - The New Global Middle Class: A Cross-Over from West to East. Washington D.C.: Wolfensohn Center for Development, Brookings, 2010.

12 Ver NERI, Marcelo - A Nova Classe Média - O lado brilhante da base da pirâmide. São Paulo: Saraiva, 2011.

13 KHARAS, Homi - "The Unprecedented Expansion of the Global Middle Class -hUn Update". In Global Economy and Development Working Paper, $\mathrm{n}^{\circ} 100$, Brookings, fevereiro de 2017. Consultado em 13.07.2017. Disponível em https://www.brookings.edu/ wp-content/uploads/2017/02/global_20170228_global-middle-class.pdf 
nominal do Bolsa Família no início de 2015." 14 Mas a nova classe média, segundo Neri, "foi muito mais sustentável que as pessoas admitiam"15, apesar do abalo do desemprego, o que se ficaria a dever aos avanços que se fizeram na educação no Brasil nos últimos 20 anos, que permitem uma maior resiliência em situações de crise.

\section{A sociedade da informação}

Um número crescente de indivíduos viverá, com enorme probabilidade, na idade da informação. A revolução das tecnologias de informação e comunicação, a universalização do uso da internet e dos telefones móveis permitem a cada cidadão não só receber e produzir informação, mas também interconectar-se através das redes sociais, tanto a nível nacional como internacional. Nas próximas décadas a revolução da sociedade de informação continuará, de acordo com o relatório Global Trends 2030 em três áreas: criação de gigantescas bases de dados, facilidade e rapidez de tratamento dos dados por Estados, empresas, mas também indivíduos; diversificação das redes sociais, que se tornarão mais complexas e, eventualmente, menos hegemónicas do que são hoje o Facebook ou o Twiter, mais flexíveis e baseadas em interesses pessoais e de grupo, e expansão dos sistemas de informação integrados, nomeadamente nas cidades, no domínio dos transportes, da energia e da saúde, mas também da vigilância e da segurança.

O Brasil é um dos países do mundo onde os cidadãos mais utilizam as redes sociais, apesar de, em 2013 , apenas $51,6 \%$ da sua população utilizar a Internet, contra $84,2 \%$ dos americanos - o que permite ainda um enorme crescimento da utilização, mas também das redes sociais. O Brasil já é o terceiro país, em número de usuários do Facebook, com 85,6

\footnotetext{
14 Marcelo Neri, entrevista à Carta do Seguro, março de 2017

15 Marcelo Neri," Uma classe ferida, mas não morta”, entrevista, FGV, jornal extra, Rio de Janeiro: 18 de dezembro de 2016.

16 National Intelligence Council, op. cit.
} 
milhões em 201617, e também o quarto em percentagem da população, com 34,5\%. O Brasil é o sexto com maior número de utilizadores do Twitter. É preciso ter em consideração que a China baniu o Twitter e o Facebook, tendo criado as suas próprias redes sociais, sendo o Weibo a mais popular, com cerca de 340 milhões de utilizadores mensais ${ }^{18}$. No que concerne ao Brasil, a tendência será, muito provavelmente, para um crescimento do número de brasileiros conectados e interconectados, consequência da sua saída da pobreza. Acresce ainda que as cidades brasileiras têm vindo a desenvolver e aplicar o conceito de Smart City, recorrendo a tecnologias da informação para reduzir os desperdícios e aumentar a participação dos cidadãos na gestão municipal.

\section{o progresso na educação é um poderoso fator de empoderamento dos cidadãos}

A educação é a questão chave da sociedade do conhecimento. Em 1990 , cerca de $73 \%$ da população mundial era alfabetizada, percentagem que subiu, segundo as Nações Unidas, para 89\% em 2014. O ritmo de alfabetização tem sido mais rápido do que o previsto e, assim, as previsões de que atingiria $90 \%$ da população mundial em 2030 estão ultrapassadas. No entanto, 72 milhões de crianças no mundo não frequentam a classe primária, 39 milhões das quais raparigas.

No Brasil, o analfabetismo diminui de forma continuada desde 2011, mas continua a ser um desafio no processo de empoderamento dos cidadãos, que dependerá, cada vez mais, do número de anos de ensino e da sua qualidade.

17 Ver Leading countries based on number of Facebook users as of April 2017 (in millions). Consultado em 20.07.2017. Disponível em https://www.statista.com/statistics/268136/top-15-countries-based-on-number-of-facebook-users/

18 Ver Twitter user numbers overtaken by China's Sina Weibo. Consultado em 20.07.2017. Disponível em http://www.bbc.com/news/technology-39947442 


\section{A emancipação das mulheres}

A emancipação das mulheres é uma das grandes revoluções do nosso tempo e irá continuar a sê-lo. As mulheres brasileiras, que constituem a maioria da população, são hoje mais ativas e educadas do que em qualquer outro momento da sua História. Mas se houve progressos significativos, ainda se está longe da paridade de género. Em 2003 as mulheres representavam $40,5 \%$ da população ocupada, valor que passou para $45,3 \%$ em $2011^{19}$. Do ponto de vista da educação, o fosso entre homens e mulheres também tem vindo a diminuir no mundo, embora com assimetrias regionais. A título de exemplo, cite-se o caso da África subsaariana, onde o grau de alfabetização dos homens era de $72,2 \%$ contra 54,6\% das mulheres (média de 2005 a 2009).

\section{Progresso na saúde para todos}

Os progressos no domínio da saúde são outro importante fator de empoderamento dos cidadãos. De acordo com o relatório do NIC, a nível mundial deverá tender-se para um "progresso continuo na saúde - incluindo melhoria da qualidade de vida para os idosos" 20 . O sinal deste progresso é a diminuição significativa das doenças epidémicas - sida, malária, diarreia e doenças respiratórias, que deverão diminuir $30 \%$ até 2030 - o que, de acordo com o mesmo relatório do NIC, provocará uma diminuição significativa na mortalidade infantil. Esta tendência também é observável na África subsaariana.

Os progressos do Brasil no domínio da saúde são atestados pela diminuição significativa da mortalidade infantil, desde 2000, mas os desafios no domínio da saúde pública, com enormes disparidades, continuarão a ser de monta na próxima década.

\footnotetext{
${ }^{19}$ IBGE - Pesquisa Mensal de emprego. Consultada em 12.07.2017. Disponível em

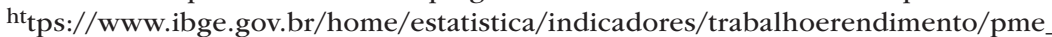
nova/Mulher_Mercado_Trabalho_Perg_Resp_2012.pdf

20 NIC, op. cit., p. 12.
} 


\section{Implicações políticas do empoderamento dos cidadãos}

Estudos de opinião demonstram que a nova classe média global converge na sua vontade de participação, de ter voz nas questões de interesse público a nível nacional. Converge também nas preocupações com o ambiente, com a corrupção e com a desigualdade. Esta convergência, que contribui para a consciência de uma humanidade comum, pode ser um fator de inclusão a nível global e também a nível nacional. Esta convergência a nível global permite falar da emergência de uma opinião pública mundial e, com ela, como escreveu Edgar Morin, a emergência de um patriotismo planetário. É esta mesma convergência que explica a tendência para a universalização dos direitos humanos, a crescente consciência ecológica e o apego ao ideal democrático, apesar de todas as ameaças que pesam sobre ele, como o demonstram numerosos inquéritos de opinião, nomeadamente do World Values Survey ou do Pew Research Center. O Brasil está mesmo entre os países aonde esse apego, segundo o inquérito do Pew, seria mais significativo ${ }^{21}$.

O empoderamento dos cidadãos tira o monopólio da política aos partidos e o monopólio da informação aos meios de comunicação tradicionais (escrita e audiovisual) e aumenta a liberdade de expressão, o que é acompanhado pela exigência de uma democracia mais participativa.

Ao mesmo tempo, a nova classe média, em muitos países do mundo, tem enormes expetativas em relação ao seu futuro. Tendo saído da pobreza nos anos de crescimento económico das potências emergentes, olha hoje para o futuro com preocupação: os governos são incapazes de responder às suas aspirações, o que produz um crescente défice de expetativas e uma, também crescente, descrença nos governos e na sua capacidade para cumprirem as suas promessas. Existe hoje uma perceção aguda de que os políticos não são capazes de cumprir as suas promessas

${ }^{21}$ Ver Pew Research Center - Global Support for Principle of Free Expression, but Opposition to Some Forms of Speech. Novembro de 2015. Consultado a 23.07.2017. Disponível em http://www.pewglobal.org/2015/11/18/1-support-for-democratic-principles/ 
porque não são os detentores do verdadeiro poder. A concentração do capital num pequeno grupo de pessoas, com uma enorme influência, é um dos fatores do atual défice democrático. No debate europeu isso está bem presente na intromissão, no debate político, das chamadas "forças do mercado", forças não eleitas e não transparentes, sobre as quais os cidadãos não têm capacidade de influência. Os eleitos usam cada vez mais o argumento "não podemos fazer, porque o mercado não deixa" e a União Europeia é cada vez mais identificada com as forças do mercado. Em França, Hollande foi eleito com um programa anti-austeridade, mas rapidamente constatou que não seria capaz de pôr em prática as suas promessas porque, como diziam círculos próximos do Presidente, as forças do mercado não deixariam.

Este défice de expetativas dá-se ao mesmo tempo que a classe média obtém instrumentos poderosos, através das redes sociais, para se manifestar e exprimir o seu descontentamento.

Nos Estados Unidos, o movimento Occupy Wall Street é expressão do descontentamento com o enorme poder de uma minoria detentora da maioria da riqueza, tornado mais evidente com os desmandos da crise financeira de 2008. O movimento declara combater "o egoísmo e a corrupção de 1\% da população", o corrosivo poder dos grandes bancos e das corporações sobre o processo democrático, que designam por corporatocracy.

A convicção de que as grandes famílias políticas não representam uma verdadeira alternativa e de que o sistema partidário, base das democracias modernas, é incapaz de se reformar, está na origem do movimento dos indignados em Espanha e do conceito de "partidocracia", realçando a exigência de uma democracia mais participativa e mais transparente.

A consequência do enfraquecimento do sistema democrático é dupla e contraditória. Por um lado, o crescimento de movimentos que exigem reformas democráticas para diminuir o peso do dinheiro na política e, por outro, o crescimento de populismos antipolítica e antipartidos. 
A descrença nos partidos políticos e nas ideologias é acompanhada por um refúgio nas políticas identitárias, particularmente religiosas, e no nacionalismo - estas são duas das características do populismo moderno. Os populistas modernos fazem das políticas de identidade e do ódio ao outro a sua bandeira. Nos países, como os europeus, em que as classes médias se sentem em declínio e temem o seu futuro, os populistas apresentam a classe média dos países emergentes como uma ameaça e é por isso que autores como Moisés Naím falam de 'choque de classes médias' ${ }^{22}$. Os riscos para a democracia acumular-se-ão, mas também aumentará a possibilidade de a tornar mais participativa e inclusiva.

As tendências "antipartidos", ou mesmo "antipolítica", são alavancadas pelas mesmas tecnologias da informação que dão aos cidadãos uma capacidade de mobilização sem precedentes.

O Brasil é um bom exemplo da combinação do défice de expetativas da classe média, com a descrença nos partidos e nas instituições democráticas, com as consequências políticas do empoderamento dos cidadãos potenciadas pela massiva utilização das redes sociais. Foi utilizando as redes sociais que em junho de 2013 explodiram as manifestações dos indignados brasileiros - à volta de uma reivindicação muito específica, o preço dos transportes -, exigindo melhores serviços públicos e uma democracia mais real, mais justa e mais participativa. As manifestações contra a Presidente Dilma em março de 2015, com o seu cunho populista e antipartidário, foram potenciadas pela mesma megatendência [de empoderamento das estruturas não-governamentais] que permitiu as manifestações de junho de 2013. Enquanto a tendência dos indignados começa a dar origem a novos partidos que se propõem revitalizar a democracia, as tendências populistas, particularmente as identitárias, são, hoje, a maior ameaça à democracia. Na Europa, a extrema-direita

22 NAÍM, Moisés - The Coming Clash of the Middle Classes. 19 de setembro de 2011. Consultado a 23.07.2017. Disponível em http://carnegieendowment.org/2011/09/19/ coming-clash-of-middle-classes-pub- 45576. 
ressurgiu como força política. No Brasil, a extrema-direita assume-se com uma agenda de indignados conservadores, como o Tea Party, com, segundo Renato Janine Ribeiro, uma agenda voltada para os costumes, com "ódio cabal aos direitos humanos"23. Os indignados conservadores têm como grupo politicamente mais influente a bancada parlamentar evangélica, com 93 deputados, grandes obreiros do impeachment da Presidente Dilma e com uma agenda ultraconservadora em questões de direitos das mulheres e LGBT; segundo a socióloga Esther Solano algumas das posições mais conservadores não teriam apoio em setores importantes dos fiéis evangélicos ${ }^{24}$.

Mas o Brasil é também um país pioneiro na adoção de mecanismos de democracia participativa. Bom exemplo desta tendência são os orçamentos participativos a nível municipal adotados por Porto Alegre e muitas outras cidades brasileiras.

\section{Difusão de poder e défice de governação}

A difusão do poder é uma megatendência resultante do peso crescente da sociedade civil, organizada em redes nacionais e transnacionais. Muitos são os exemplos notáveis do papel das grandes organizações não governamentais, como os Médicos sem Fronteiras, e fundações filantrópicas, como a Fundação Gates, que assume uma enorme parte das responsabilidades internacionais na luta contra a malária. Os governos também partilham cada vez mais o poder com as cidades, nomeadamente com as megacidades, que, em consequência da urbanização, concentram enormes recursos e responsabilidades. Em consequência da tendência para a privatização trazida pelo neoliberalismo, os Estados foram transferindo para o sector não estatal responsabilidades centrais como a saúde

\footnotetext{
23 Intervenção no seminário do IRI/GG10: Os cidadãos e o futuro do multilateralismo num mundo policêntrico em 2030. São Paulo, 27 de abril de 2015, notas do autor.

${ }^{24}$ Ver Marcha para Jesus foge da polarização entre esquerda e direita. Consultado a 26.07.2017. Disponível em https://www.cartacapital.com.br/politica/marcha-para-jesus-foge-da-polarizacao-entre-esquerda-e-direita
} 
e mesmo a segurança, com riscos elevados para os direitos humanos e para a justiça, como se viu no Iraque.

Os políticos que exerceram responsabilidades governamentais no Brasil nas últimas duas décadas puderam constatar como o poder é mais frágil e difuso, como fez Fernando Henrique Cardoso; entrevistado por Moisés Naím para o seu livro The End of Power ${ }^{25}$ abordou os limites ao poder de qualquer presidente, salientando "o fosso entre o poder real e o que as pessoas esperam é a pressão mais difícil que qualquer chefe de governo tem que enfrentar." Certamente que os Presidentes Lula e Dilma, que lhe sucederam, não fariam afirmações muito diferentes, embora com o incremento significativo das políticas sociais do Estado brasileiro tenham mostrado que o governo tinha ainda poderes consideráveis para inverter problemas graves como a miséria.

Num momento de crise como o Brasil atravessa, o poder da sociedade civil brasileira é hoje incontestável não só no domínio interno mas também externo. De todos os países membros dos BRICS o Brasil é certamente aquele aonde a sociedade civil é mais poderosa e diversificada, em domínios como os direitos humanos, a educação, a saúde, o ambiente ou a coesão social.

A nível internacional, o impacto da sociedade civil brasileira, das suas organizações não governamentais e das suas redes sociais, é uma componente importante do seu soft power ou poder de atração. Foi em Porto Alegre que nasceu o Fórum Social Mundial. que viria a ter um enorme impacto internacional e a afirmar-se mesmo como a alternativa cidadã ao Fórum Económico Mundial de Davos.

No Brasil, as empresas de segurança privada substituem-se ao Estado na proteção das classes do topo da pirâmide, o que tende a criar uma enorme assimetria na segurança dos cidadãos. Segundo o Mapa da Violência, das 56.065 pessoas assassinadas no Brasil em 2012, 41.127

25 NAIM, Moisés - The End of Power: From Boardrooms to Battlefields and Churches to States, Why Being in Charge Isn't What It Used To Be, Nova Iorque: Basic Books, 2013. 
eram negros e mestiços e 14.928 brancos $^{26}$. Esta tendência tem vindo a agravar-se e não deverá alterar-se nos próximos anos, o que também contribui para o descontentamento da nova classe média.

As cidades brasileiras serão cada vez mais megacidades, poderosos centros de poder político e económico - São Paulo deverá atingir, em 2030, 22 milhões de habitantes e o Rio de Janeiro 13 milhões, e estarão entre as 20 maiores cidades do mundo, segundo as Nações Unidas. O enorme poder económico e demográfico das grandes cidades brasileiras irá alterar a relação entre o poder central, o dos Estados da federação e o municipal.

Com o poder central fragilizado, a governação a nível nacional tem que assumir cada vez mais o princípio da subsidiariedade, com uma concomitante descentralização de poderes, por uma questão de eficácia mas também para conter a fragmentação, garantindo em paralelo que as discrepâncias regionais não se agravem.

\section{O Brasil num mundo policêntrico}

O mundo está a evoluir para um mundo policêntrico pós-hegemónico e pós-ocidental. Por policentrismo entende-se a existência de uma multiplicidade de atores, grandes potências, potências média e outras, sem que nenhuma tenha condições para estabelecer a hegemonia.

O mundo pós-hegemónico tem vários centros de poder económico, e muito provavelmente o mesmo acontecerá do ponto de vista ideológico. De um mundo politicamente heterogéneo bipolar (democracia versus sovietismo ${ }^{27}$ ), passámos para um mundo de enorme desconfiança perante as ideologias políticas, o que deu origem também a um enorme pluralis-

26 Ver Número de negros assassinados aumenta e de brancos diminui no Brasil. Consultado em 21.07.2017. Disponível em https://pragmatismopolitico.jusbrasil.com.br/noticias/125585153/numero-de-negros-assassinados-aumenta-e-de-brancos-diminui-no-brasil

27 Ver ARON, Raymond - Paix et guerre entre les nations. Paris: Calmann-Lévy, $8^{\mathrm{a}}$ ed.. com prefácio inédito do autor, 1984. 
mo ideológico, onde nenhuma ideologia, nem mesmo as de inspiração religiosa, parece ter tendência para se universalizar.

A tendência para o policentrismo irá muito provavelmente consolidar-se nos próximos anos, com uma concentração do poder económico na Ásia, com a China e a Índia a representarem cerca de 1/3 dos habitantes da Terra. A China já é a principal potência económica em termos de PIB em Paridade de Poder de Compra (PPC) e todos os estudos de prospetiva indicam o crescimento significativo da economia indiana - a fronteira entre a Índia e a China tenderá a ser o centro do Mundo. Isso mesmo foi reconhecido pelas organizações dos serviços de informação americanos, reunidas no National Intelligence Council desde 2008, no seu relatório quadrienal, ao assumirem o relativo declínio dos Estados Unidos, o que reafirmaram em 2012: "Numa mudança tectónica, em 2030 a Ásia terá ultrapassado o poder conjunto da América do Norte e da Europa em termos de PIB, dimensão da população, gastos militares e investimento tecnológico." 28

Não serão as políticas de America First, de nacionalismo económico, que irão alterar este relativo declínio norte-americano e poderão mesmo agravá-lo.

Mesmo assim, os Estados Unidos e a Europa, desde que unida, ainda têm trunfos significativos para pesar nos destinos do mundo. Os Estados Unidos deverão continuar a ser a única superpotência militar, agora sem um poder económico que permita a hegemonia, mas poderão, no período pós-Trump, assumir, como tinha feito Obama, a necessidade de contribuírem para o reforço da governação global no quadro das Nações Unidas e do G20. A União Europeia, se conseguir sair da atual crise e preservar o seu modelo de sociedade aberta, será, pela sua defesa do multilateralismo em questões vitais como a contenção do aquecimento global, um ator indispensável da ordem internacional e poderá voltar

28 NIC, op.cit. 
a ser uma fonte de inspiração para novos projetos de cooperação e integração regional.

Todos os indicadores, até 2014, mostravam também a emergência do Brasil, embora as análises dos mesmos começassem a questionar a possibilidade do gigante latino-americano ser capaz de atingir o nível das grandes potências, sendo provável que se afirmasse como a primeira das potências médias.

Não é apenas a tendência para a emergência da Ásia, do ponto de vista económico, em termos de PIB, mas são as projeções que combinam vários elementos de poder, a que se convencionou chamar de material power $^{29}$ que indicam o declínio: relativo, no caso dos EUA, muito mais pronunciado no que se refere à União Europeia.

Estes indicadores mostram também a emergência do Brasil. Nos cálculos feitos em 2012 da distribuição do material power era considerado provável que, alguns anos antes de 2030, ultrapassasse a Rússia, com o Brasil a atingir 2,6 e a Rússia a decair para 2,530 mas dadas as dificuldades atuais do Brasil é provável que o crescimento do material power do Brasil seja mais lento.

De acordo com o relatório do NIC "Na América Latina, os próximos 15 anos irão provavelmente confirmar a posição do Brasil enquanto 'colosso do Sul', reforçando a sua posição relativamente ao México e à Colômbia - apesar das boas perspetivas de crescimento destes dois países". ${ }^{31}$ É preciso notar que este relatório do NIC foi publicado em 2012, antes da crise brasileira.

Outras influentes potências médias, de acordo com os relatórios mencionados, serão muito provavelmente o Irão, a Turquia, a Indonésia, o México, a Colômbia, a Nigéria e a Etiópia, cuja influência dependerá,

\footnotetext{
29 Índice complexo que associa o poder económico com o militar e o tecnológico.

${ }^{30}$ VASCONCELOS, Álvaro (ed.) - Global Trends 2030: Citizens in an Interconnected and Polycentric World, op. cit. p.110

31 NIC, op. cit..
} 
em boa medida, da capacidade para promoverem a cooperação regional com os seus vizinhos.

A emergência do Brasil não fará necessariamente do país uma grande potência mundial, posição a ser ocupada pelos EUA, pela China e pela Índia, mas o Brasil deverá ser uma potência média influente - as relações com a Colômbia serão críticas para garantir a necessária cooperação na América do Sul.

O papel futuro da União Europeia como ator global é difícil de prever, mas certamente a Alemanha, a França e, muito provavelmente, a Grã-Bretanha serão influentes potências médias, que se apoiarão num espaço de cooperação europeia mais ou menos profundo.

O que diferenciará as potências globais das potências médias será a capacidade de ter um papel significativo na resolução das grandes questões globais, incluindo na área da segurança, e o papel central na resolução dos problemas regionais. É esta a diferença entre potências regionais e globais.

\section{Soft power: um fator do poder}

No futuro, o peso internacional de um Estado dependerá muito mais do seu soft power, o poder de convencer, do que do seu hard power, o poder de coagir. Num mundo de difusão do poder, de grandes redes transnacionais e da sociedade da informação, os países deixaram de ser ilhas isoladas, em que o que se passa no interior das suas fronteiras só aos seus cidadãos interessa e diz respeito. O escrutínio internacional será cada vez maior e a imagem que dele resultar terá enormes repercussões na capacidade de um Estado promover a sua agenda internacional.

Em 2011, Joseph Nye definiu soft power como "a capacidade de influenciar terceiros através de meios colaborativos de definição de agenda, de persuasão, de congregar uma atração positiva para alcançar os resultados desejados". ${ }^{32} \mathrm{O}$ soft power é o poder de atração de um dado

\footnotetext{
32 NYE, Joseph Jr. - The Future of Power, Nova Iorque: Public Affairs, 2011.
} 
país em relação aos cidadãos de outros países, poder que depende de vários fatores, nomeadamente do sucesso do seu modelo político, social e económico e da popularidade da sua cultura.

Apesar de ser difícil quantificar o soft power, um dos métodos são as sondagens de opinião internacionais sobre as perceções dos países, como as que são levadas a cabo regularmente pelo Pew Research Center. Em junho de 2014, foi realizada uma sondagem sobre o Brasili33 (ver Tabela II). De acordo com outras pesquisas, a imagem positiva do Brasil resultaria da sua transição democrática e do seu modelo social. ${ }^{34}$

Tabela II - Perceção sobre o Brasil

\begin{tabular}{|l|c|c|}
\hline & Favorável & Desfavorável \\
\hline América Latina & $58 \%$ & $18 \%$ \\
\hline Ásia & $55 \%$ & $25 \%$ \\
\hline Europa & $51 \%$ & $34 \%$ \\
\hline Oriente Médio & $44 \%$ & $36 \%$ \\
\hline
\end{tabular}

Fonte: Pew Research Center, junho 2014

Podemos dizer que o soft power do Brasil, de acordo com estas sondagens, é bastante elevado, em particular na América Latina, e assim se poderá manter se a sua democracia e o processo de inclusão social continuarem a consolidar-se. Graças ao seu soft power o Brasil foi nas últimas décadas uma voz respeitada e influente em questões como a agenda do desenvolvimento, do ambiente e do comércio internacional.

A crise brasileira ainda não parece ter afetado significativamente a imagem do Brasil 35 mas poderá vir a miná-lo gravemente se a saída para a atual crise política for a destruição do acquis social ou a emergência

33 On Eve of World Cup, Brazil Well-Regarded in Much of the World, disponível em http://www.pewglobal.org/2014/06/11/on-eve-of-world-cup-brazil-well-regarded-in-much-of-the-world/

${ }^{34}$ Ver VASCONCELOS, Álvaro - O Brasil e as mudanças no Mundo Árabe, working paper IRI/USP, 2015.

35 VASCONCELOS, Álvaro - O Brasil e o Oriente Médio Percepções e prioridades, IRI/ USP, 2016 (inédito). 
de um regime autoritário e populista. O soft power brasileiro facilita a sua ação diplomática e, se combinado com uma capacidade de contribuir para a manutenção da paz em situações de crise, poderá fazer do Brasil um importante ator internacional, com responsabilidades particulares na América do Sul.

\section{A governança mundial entre inclusão e fragmentação}

Nenhum poder, em 2030, será uma potência hegemónica capaz, por si só, de ditar as regras do sistema ou resolver os problemas mundiais e esta constatação é tão verdadeira para os Estados Unidos como, e ainda mais, para a China. A governança mundial, num mundo de difusão de poder, deverá depender cada vez mais de uma multiplicidade de atores, da capacidade de integrar, no mesmo esforço, uma multiplicidade de redes - sejam elas não estais ou estatais. As organizações terão de se reformar, para incluírem a nova realidade de poder internacional.

A reforma das organizações multilaterais tem-se mostrado particularmente difícil, mesmo no período em que esteve na presidência dos Estados Unidos um presidente multilateralista como Obama; com Trump será muito provavelmente impossível. Neste contexto, as potências que emergiram, como os BRICS, terão tendência para criar organizações alternativas, como é o caso do Novo Banco de Desenvolvimento dos BRICS ou do Asian Infrastructure Investment Bank (AIIB), uma iniciativa chinesa. Iniciativas que respondem ao facto de o Banco Mundial e de o FMI ainda serem organizações dominadas pelos EUA e pelos europeus e de não corresponderem às mudanças significativas que tiveram lugar na distribuição de riqueza. Depois das esperanças de uma regulação multilateral do comércio mundial assistimos hoje a uma paralisia das negociações multilaterais, como é o caso da Organização Mundial do Comércio, e à procura no bilateralismo dos mega-acordos, como o que está a ser negociado entre a União Europeia e os Estados Unidos ou entre os Estados Unidos e os seus parceiros asiáticos. 
Mas onde essa falta de inclusão se faz sentir de forma mais significativa é no Conselho de Segurança das Nações Unidas, com graves repercussões na segurança internacional. A Síria é o exemplo trágico da incapacidade de resposta do atual sistema internacional.

O Acordo de Paris sobre o aquecimento global é, no entanto, a prova de que a consciência da existência de desafios comuns tende a aumentar e de que é possível encontrar novas formas de governação mundial mais inclusivas.

Se para os Estados Unidos e para a China um mundo em que impere a política de potência, o bilateralismo e a fragmentação não colocam desafios existenciais, o mesmo não se pode afirmar em relação à União Europeia ou às potências médias, como o Brasil. O interesse do Brasil num mundo regido por regras multilaterais tem sido uma constante da sua diplomacia. O foco estará cada vez mais em como contribuir para a solução multilateral dos grandes problemas internacionais, sejam os das alterações climáticas, os do comércio internacional ou os da segurança.

Isto significa, para as potências que emergiram, demonstrarem a superioridade do multilateralismo, o que implica evoluírem de um multilateralismo concebido para travar o poder dos mais poderosos, para um multilateralismo eficaz, isto é, virado para a solução dos problemas.

\section{Conclusões}

A ascensão de uma classe média global, fortalecida pela educação, a emancipação das mulheres e as tecnologias da informação são tanto uma oportunidade para inclusão como um fator de fragmentação.

Falo em inclusão porque há um crescente sentimento de humanidade comum e uma convergência a respeito da definição dos grandes desafios globais: participação política, alterações climáticas, desigualdade e corrupção. A fragmentação decorre de um défice entre expectativas e governança, de uma desconfiança em relação aos partidos políticos, da ascensão do nacionalismo populista e das políticas de identidade que se alimentam das resistências à diversidade e de um choque entre classes 
médias - das classes médias declinantes na Europa e nos EUA, de um lado, e das classes médias em ascensão das potências emergentes, de outro.

Estes fatores de inclusão e de fragmentação coexistem com a difusão do poder e as dificuldades que encontram os governos para fornecerem bens públicos, no âmbito nacional, e a difusão do poder no âmbito global, enquanto ingressamos num mundo policêntrico, que faz do multilateralismo algo mais necessário, mas também mais difícil. Todas estas tendências contribuem para que seja muito difícil prever se o mundo em 2030 será mais inclusivo, ou mais fragmentado. Ambos os cenários são possíveis.

\section{o futuro para além da crise}

No caso do Brasil há uma dificuldade de monta para arriscar um prognóstico sobre o futuro, que é a dimensão da atual crise, com um governo transitório e de pouquíssima legitimidade que procura levar a cabo um programa que tinha sido rejeitado nas eleições, ao mesmo que se acumulam casos de corrupção que atingem o governo e todos os partidos. A consequência da crise atual, no tempo curto, é um grave impasse político, as dificuldades para lidar com a crise económica e uma regressão social, que põe em causa as conquistas no combate à pobreza e o futuro da nova classe média. Situação critica que coloca em questão a conclusão dos relatórios de tendências globais mencionados, nos quais o Brasil emergia como uma potência global no horizonte de 2030. Conseguirá o Brasil retomar o estatuto de ator global? Ou irá o Brasil continuar numa via ascendente, com um ritmo mais lento, como tudo leva a crer? 


\section{Cenários para o Brasil}

O Brasil, país democrático e de enorme diversidade humana, é um laboratório extraordinário das mudanças que estão a ter lugar no mundo.

O Brasil é um laboratório da tendência para a inclusão, tanto interna como em termos internacionais:

a) pela emergência da classe média, empoderada pelas tecnologias da informação e pela educação, com as suas exigências de uma democracia mais participativa, mais transparente, mais justa e menos corrupta - tudo fatores que podem contribuir para uma maior inclusão a nível interno;

b) o Brasil é uma potência emergente, a nível global, com um significativo soft power, que será cada vez mais chamado a participar na solução multilateral dos problemas globais e, consequentemente, a contribuir para a inclusão a nível internacional.

O Brasil é um laboratório dos riscos de fragmentação:

a) pela resistência das forças políticas dominantes a uma reforma política que reconstrua a confiança na democracia, aumente a representatividade dos eleitos e combata eficazmente a corrupção da política e dos políticos;

b) pelo receio da nova classe média de um retrocesso social e dos riscos de diminuição do ritmo de saída da pobreza, mas também pelo crescente papel de correntes religiosas que se opõem à unidade na diversidade, a que acresce a crescente polarização política e ideológica entre diferentes correntes partidárias;

c) pela resistência de diversos setores brasileiros a um maior compromisso internacional do país.

No caso brasileiro o cenário da inclusão, a nível interno, e de contributo para um multilateralismo inclusivo, é o mais provável, mas não se pode excluir o retrocesso na inclusão social e na qualidade da democracia brasileira, sendo muito pouco plausível o regresso do autoritarismo, embora o risco da vitória de um líder populista à Trump, nos próximos anos, não seja de descartar. 


\section{Referências Bibliográficas}

ARON, Raymond - Paix et guerre entre les nations. Paris: Calmann-Lévy, $8^{\mathrm{a}}$ ed.. com prefácio inédito do autor, 1984.

KHARAS, Homi - "The Unprecedented Expansion of the Global Middle Class - Un Update”. In Global Economy and Development Working Paper, $\mathrm{n}^{\circ} 100$, Brookings, Fevereiro de 2017. Consultado em 13.07.2017. Disponível em https://www.brookings.edu/wp-content/uploads/2017/02/global_20170228_ global-middle-class.pdf

KHARAS, H. e GERTZ, G. - The New Global Middle Class: A Cross-Over from West to East. Washington D.C.: Wolfensohn Center for Development, Brookings, 2010.

NAÍM, Moisés - The Coming Clash of the Middle Classes. 19 de setembro de 2011. Consultado a 23.07.2017. Disponível em http://carnegieendowment. org/2011/09/19/coming-clash-of-middle-classes-pub-45576.

NAIM, Moisés - The End of Power: From Boardrooms to Battlefields and Churches to States, Why Being in Charge Isn't What It Used To Be, Nova Iorque: Basic Books, 2013.

National Intelligence Council - Global trends 2030: Alternative worlds. Washington DC: NIC, 2012. Consultado em 13.07.2017. Disponível em: https://globaltrends2030. files.wordpress.com/2012/11/global-trends-2030-november2012.pdf NERI, Marcelo - A Nova Classe Média - O lado brilhante da base da pirâmide. São Paulo: Saraiva, 2011.

NYE, Joseph Jr. - The Future of Power, Nova Iorque: Public Affairs, 2011.

ONU, Department of Economic and Social Affairs, Population Division - World Population Prospects: The 2017 Revision, Key Findings and Advance Tables. Working Paper No. ESA/P/WP/248, 2017. Consultado em 20.07.2017. Disponível em https://esa.un.org/unpd/wpp/Publications/Files/WPP2017_KeyFindings.pdf

ONU, Department of Economic and Social Affairs, Population Division - International Migration Report 2015: Highlights. (ST/ESA/SER.A/375), 2016. Consultado em 23.07.2017. Disponível em http://www.un.org/en/development/desa/population/migration/publications/migrationreport/docs/MigrationReport2015_Highlights.pdf

TALEB, Nassim N. - The Black Swan: The Impact of the Highly Improbable. Nova Iorque: Random House, 2007.

VASCONCELOS, Álvaro - O Brasil e as mudanças no Mundo Árabe, working paper IRI/USP, 2015.

VASCONCELOS, Álvaro - O Brasil e o Oriente Médio Percepções e prioridades, IRI/USP, 2016 (inédito). 
VASCONCELOS, Álvaro (ed.) - Global Trends 2030: Citizens in an Interconnected and Polycentric World. Paris: EUISS, 2012. Consultado em 13.07.2017. Disponível em https://www.iss.europa.eu/sites/default/files/EUISSFiles/ ESPAS_report_01_0.pdf. 